\title{
Research to Action: Lessons and Learning with the Evidence Project
}

Robin Keeley

Karen Hardee

Follow this and additional works at: https://knowledgecommons.popcouncil.org/departments_sbsr-rh How does access to this work benefit you? Let us know!

\section{Recommended Citation}

Keeley, Robin and Karen Hardee. 2017. "Research to Action: Lessons and Learning with the Evidence Project." Meeting report. Washington, DC: Population Council, The Evidence Project. 
Research to Action

Lessons and Learning with the Evidence Project

IUSSP INTERNATIONAL POPULATION CONFERENCE

$z$
11
11
27
0
0
0
0
0
0

SIDE EVENT

CAPE TOWN, SOUTH AFRICA

OCTOBER 2017

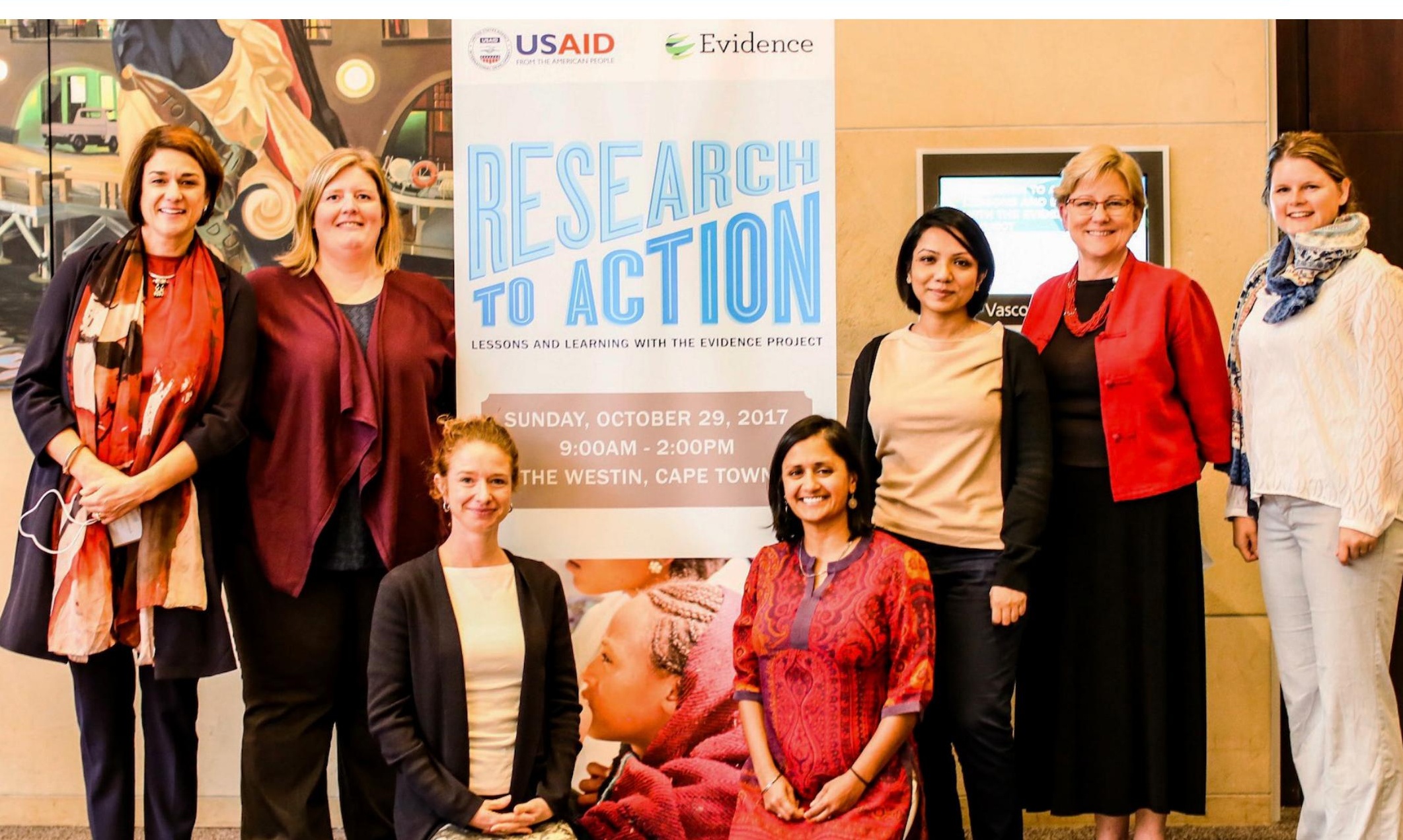





\section{Research to Action}

Lessons and Learning with the Evidence Project

\begin{tabular}{l} 
IUSSP INTERNATIONAL POPULATION CONFERENCE \\
SIDE EVENT \\
CAPE TOWN, SOUTH AFRICA \\
OCTOBER 2017 \\
\hline
\end{tabular}

\begin{tabular}{l} 
IUSSP INTERNATIONAL POPULATION CONFERENCE \\
SIDE EVENT \\
CAPE TOWN, SOUTH AFRICA \\
OCTOBER 2017 \\
\hline
\end{tabular}

\begin{tabular}{l} 
IUSSP INTERNATIONAL POPULATION CONFERENCE \\
SIDE EVENT \\
CAPE TOWN, SOUTH AFRICA \\
OCTOBER 2017 \\
\hline
\end{tabular}

\begin{tabular}{l} 
IUSSP INTERNATIONAL POPULATION CONFERENCE \\
SIDE EVENT \\
CAPE TOWN, SOUTH AFRICA \\
OCTOBER 2017 \\
\hline
\end{tabular} 


\author{
The Evidence Project \\ Population Council \\ 4301 Connecticut Avenue, NW, Suite 280 \\ Washington, DC 20008 USA \\ tel +1 2022379400 \\ evidenceproject.popcouncil.org
}

OSAID

The Evidence Project is made possible by the generous support of the American people through the United States Agency for International Development (USAID) under the terms of cooperative agreement no. AID-OAA-A-13-00087. The contents of this document are the sole responsibility of the Evidence Project and Population Council and do not necessarily reflect the views of USAID or the United States Government.

\title{
Evidence
}

The Evidence Project uses implementation science-the strategic generation, translation, and use of evidence-to strengthen and scale up family planning and reproductive health programs to reduce unintended pregnancies worldwide. The Evidence Project is led by the Population Council in partnership with INDEPTH Network, International Planned Parenthood Federation, PATH, Population Reference Bureau, and a University Research Network.

\section{- POPULATION COUNCIL}

Ideas. Evidence. Impact.
The Population Council confronts critical health and development issues-from stopping the spread of HIV to improving reproductive health and ensuring that young people lead full and productive lives. Through biomedical, social science, and public health research in 50 countries, we work with our partners to deliver solutions that lead to more effective policies, programs, and technologies that improve lives around the world. Established in 1952 and headquartered in New York, the Council is a nongovernmental, nonprofit organization governed by an international board of trustees.

Published in February 2018..

Suggested citation: Keeley, Robin \& Karen Hardee. 2017. "Research to Action: Lessons and Learning with the Evidence Project," Meeting Report. Washington, DC: Population Council, The Evidence Project.

Photo credit for all photos in report: Ashish Bajracharya, 2017

(C) 2018. The Population Council, Inc.

\section{Acknowledgments}

This workshop was funded by the United States Agency for International Development (USAID) through the Evidence Project, in collaboration with the TRAction Project. The organizing committee included: Karen Hardee and Aparna Jain from the Population Council, Robin Keeley from PATH, and Kate Gilles and Anneka Van Scoyoc from PRB, all from the Evidence Project. We thank Ann Blanc and Michelle Hindin of the Population Council for their remarks at the meeting. We thank the presenters: Laura Reichenbach, Sigma Ainul, and Aparna Jain from the Evidence Project/Population Council, and, Vicky Boydell from the Evidence Project/IPPF. We appreciate Mihira Karra, Erika Martin, and Erika Houghtaling of USAID for supporting the Evidence Project to convene this meeting.

\section{List of Acronyms \\ AFHC Adolescent friendly health corners \\ ASRH Adolescent sexual and reproductive health \\ IPC International Population Conference \\ IUSSP International Union for the Scientific Study of Population \\ PPMV Proprietary and patent medicine vendors \\ SRH Sexual and reproductive health}




\section{Table of Contents}

Objectives .......................................................................................... 2

Welcome and Opening Remarks ................................................ 2

Panel: Research Utilization in Action...................................... 3

Research Utilization Approaches in the Evidence Project ................... 3

Evidence Project Research Utilization Process: Study Design, Implementation, and Use............................................................................ 4

Example of Research Utilization for Policy Change: Proprietary and Patent Medical Vendor's Provision of Injectable Contraception in Nigeria....................................................................................................... 5

Example of Research Utilization to Improve New Programming: Adolescent Sexual and Reproductive Health in Bangladesh ........... 5

Example of Research Utilization to Scale Up Programming ............. 6

Example of Research Utilization in the Context of an Emerging Evidence Base

Discussion........................................................................................... 10

Closing Remarks ............................................................................... 12

Next Steps .......................................................................................... 13

Appendix 1 | Meeting Agenda ..................................................... 14

Appendix 2 | Presentations ............................................................. 15 


\section{Objectives}

The Evidence Project hosted this event adjacent to the International Population Conference (IPC) of the International Union for the Scientific Study of Population (IUSSP). Participants included academics, researchers, program designers, funders and implementers from a range of countries.

The objective of the meeting was to build the capacity of participants to increase research utilization as well as to highlight work done by the project in this area. See Appendix 1 for the agenda of the meeting. The meeting had three objectives to help participants:

- Gain an understanding of research utilization in the context of the Evidence Project.

- Learn about research utilization in different research contexts.

- Discuss and learn from others about challenges and ideas around research utilization.

\section{Welcome and Opening Remarks}

Karen Hardee, director of the Evidence Project, opened the meeting, set the stage for the day, and served as the facilitator of the meeting. Ann Blanc, vice president of social and behavioral research at the Population Council, made introductory remarks. She noted that, as a researcher, she has gained an appreciation for the importance of research utilization and the role researchers and research organizations can play in ensuring that research is considered in policymaking and program implementation. She is spearheading an initiative at the Population Council to better understand the impact of the organization's research and to determine pathways for enhancing use of evidence in policies and programs. 


\section{Panel: Research Utilization in Action}

Evidence Project staff delivered five presentations, beginning with an overview of the Evidence Project's research utilization strategy and followed by four examples. The first example illustrated how research has been shaped to inform policy change. The second example demonstrated how research improved a new practice. The third example looked at scaling up a practice, and the fourth examined research utilization in the context of an emerging practice. See Appendix 2 for the presentations.

\section{Research Utilization Approaches in the Evidence Project}

Robin Keeley, the project's research utilization specialist from PATH, presented an overview of the research utilization process used by the Evidence Project. Two of the project's early working papers focused on the questions:

1. What role does research plays in family planning policy, program, and practice decision making?

2. How can the role of research in family planning policy, program, and practice decision making be expanded?

These papers, and discussions around these same questions with government decision makers at a meeting in 2016, generated the core ideas around which the Evidence Project's research utilization is based, including:

- Building relationships between researchers and decisionmakers.

- Using intermediaries, or champions, to help researchers and decisionmakers communicate.

- Finding more effective ways to package and communicate findings.

- Grounding research from the start in an understanding of the health system.

- Building research utilization, and its associated costs, into study protocols and budgets from the start.

Robin also discussed the parallel processes of research and research utilization. She demonstrated how, from the study design phase and through the study implementation phase, utilization can and should be considered and incorporated into the research process (Figure 1). She emphasized that research utilization should not be postponed until after research is completed. Though the presentation depicted the processes as linear, participants noted that iteration and course correction should be anticipated during the process. Dissemination meetings are often thought of as the "use" of the research findings. However, the Evidence Project considers this just one more phase in the utilization process. Other activities should be planned, as appropriate, to operationalize the results and can include things such as:

- Convening stakeholder meetings.

- Working with champions to influence key decision makers.

- Developing advocacy messages and materials.

- Providing technical assistance to inform program change. 


\section{Figure 1}

Evidence Project Research Utilization Process: Study Design, Implementation, and Use

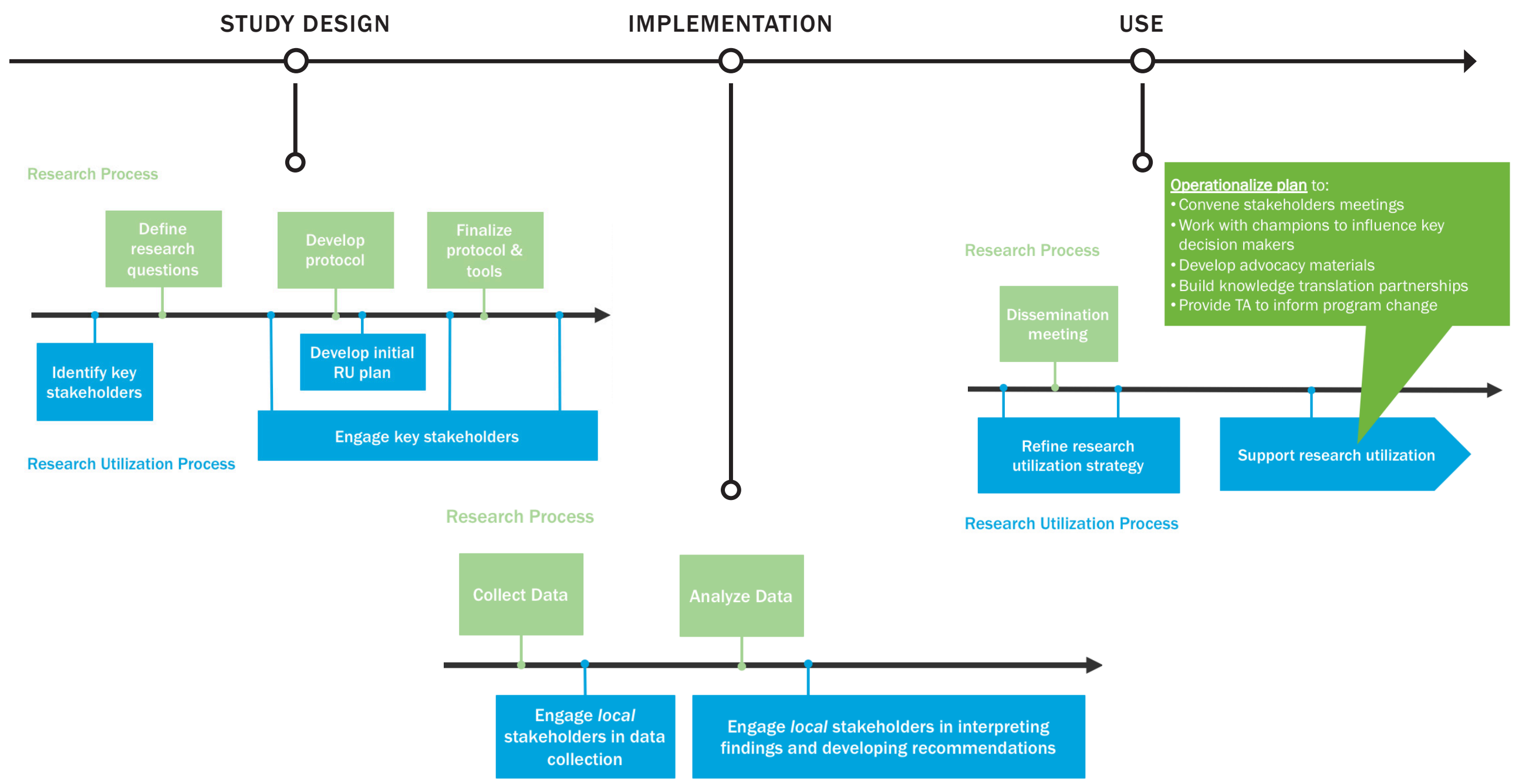

Research Utilization Process 


\section{Example of Research Utilization for Policy Change: Proprietary and Patent Medical Vendor's Provision of Injectable Contraception in Nigeria}

Laura Reichenbach, former deputy director for research on the Evidence Project, now director of the USAIDfunded Breakthrough Research project, presented an example of how research utilization can affect policy change. She explained the project's work with proprietary and patent medicine vendors (PPMV) and injectable contraceptives in Nigeria. This activity has built on an existing base of evidence on PPMVs. The research team is testing a set of interventions to increase the capacity of PPMVs to provide quality information and services that are acceptable for clients who want progesterone-only injectable contraceptives. The evidence generated by this research will inform revisions to the laws and regulations governing the delivery of contraceptive counseling and services by PPMVs.

Stakeholders were engaged early in the study process. This led to an expansion of the original study question about PPMVs' capacity for selling, counseling and referring for injectable services to include the study of whether PPMVs can be trained to safely administer injectables. This stakeholder engagement ensured that the study provided the evidence policymakers will need to address the question of PPMVs administering injectables. Early stakeholder engagement also allowed the study team to hear from detractors of PPMV delivery of injectables and try to address their concerns as the

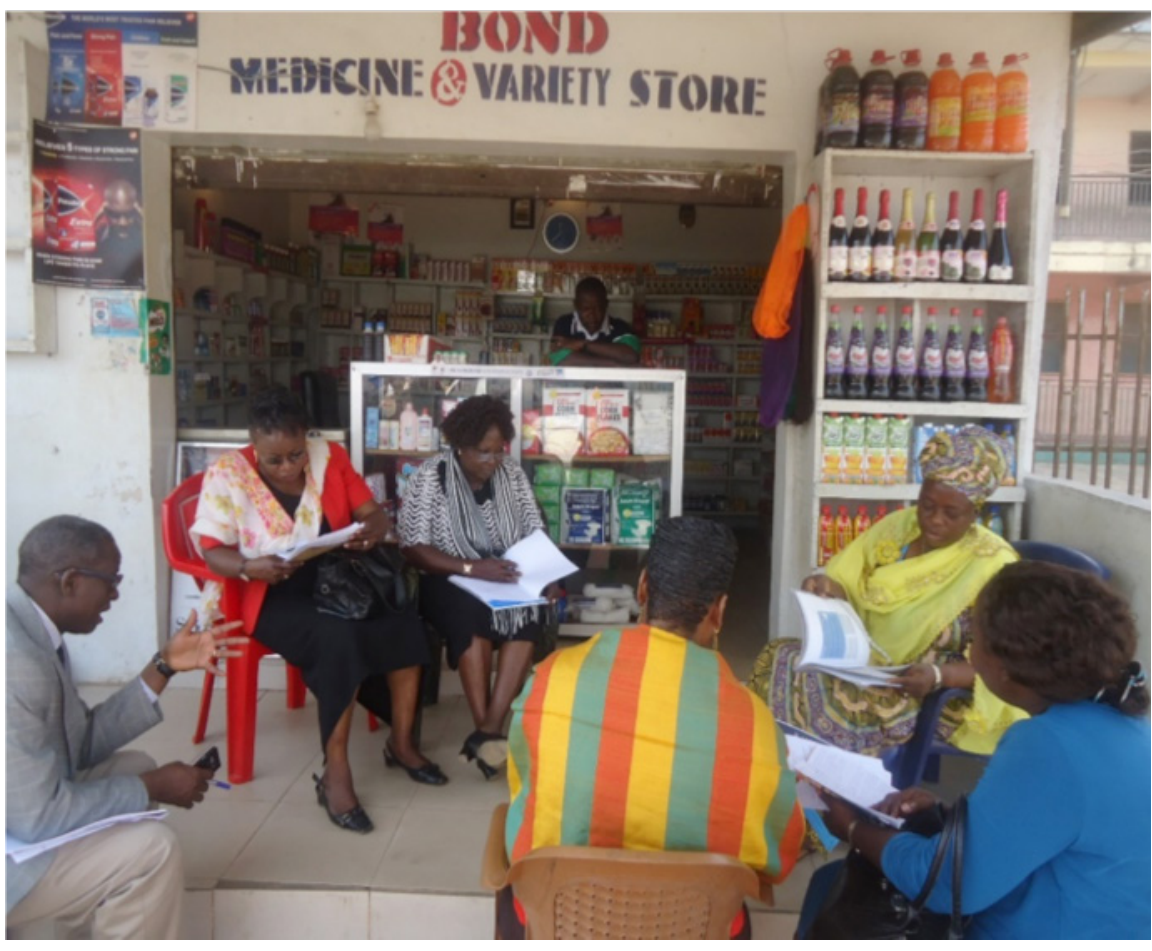
study proceeds. Federal, state, and local health officials have been involved in every aspect of the study. They attend PPMV monitoring visits to see and understand whether training has increased the capacity of PPMVs to administer injectable contraceptives. Monitoring data is also used to assess needs for supportive supervision and refresher training. This study is being conducted in two phases. Results from the first phase of the study have been used to inform and modify the design of the second phase. This includes using results of monitoring visits and post-training tests to modify the training curriculum and to add testing the use of job aids to improve PPMVs compliance with best practices. The activity team will also use a variety of methods to communicate study progress and results to key decision makers, including both written and multi-media messaging.

\section{Example of Research Utilization to Improve New Programming: Adolescent Sexual and Reproductive Health in Bangladesh}

Sigma Ainul, program officer from the Population Council's office in Bangladesh, presented on how research can be used to improve new programming. She used examples from the Evidence Project's work in adolescent 
sexual and reproductive health (ASRH). She discussed a situation analysis that the project conducted to identify existing ASRH programing and gaps. Three types of interventions were identified: (1) facility-based models; (2) community/safe space models; and, (3) school-based models. The analysis found that supply and demand factors pose barriers to use of clinical ASRH services. Current government policy limits the provision of sexual and reproductive health $(\mathrm{SRH})$ services (including contraceptives or sexually transmitted infections [STI] services) to married adolescents. There is stigma associated with adolescents accessing services; communities often view health facilities as "family planning clinics." Adolescents perceived primary healthcare services as lacking respect, privacy and confidentiality.

In 2016, the Ministry of Health and Family Welfare in Bangladesh set up ten pilot adolescent friendly health corners (AFHC) to extend ASRH services to married and unmarried girls and boys (see Box 1). At the request of the government, the Evidence Project assessed the AFHC model and found that it successfully pulled in unmarried adolescent girls, but not boys. Overall adolescent girls expressed satisfaction with the service providers. There were several challenges identified. The government is using the results of the assessment to improve the AFHS model including: (1) revising the training module; (2) reviewing and refining AFHS criteria; and, (3) regularly monitoring the quality and performance of AFHCs.

\section{Example of Research Utilization to Scale Up Programming}

\section{Preventing Child Marriage in Ethiopia}

Aparna Jain, deputy director for research on the Evidence Annabel Erulkar. Her work focuses on preventing child marriage. The work has been done in three phases. Phase one was called Berhane Hewan. The pilot was designed based on existing evidence of four interventions that help to prevent child marriage:

- Address social norms through community conversations.

- Provide school supplies to encourage retention in school.

- Provide conditional asset transfers to encourage girls to remain unmarried and in school.

- Establish married girls' groups to improve life skills and reproductive health knowledge. 
The pilot found positive results including that girls aged 10 - 14 were 90 percent less likely to be married in intervention sites than in control sites. Local partners questioned whether the multi-component design could feasibly be scaled-up, especially in the absence of costing data.

In phase two of Berhane Hewan, the research team addressed the question of scale-up. The team tested simplified, more easily scaled-up program components, in different geographic areas, to identify a minimum basic package of interventions while retaining fidelity to the original intervention. Costing data was also collected. In addition to informing scale-up, phase two also provided information on how to refine and improve design and implementation of child marriage prevention programs, including (a) identifying and targeting specific geographic sub-regional locations where child marriage is most prevalent and (b) paying attention to the coverage of interventions on the ground.

The information from phase two was then used to inform the scale-up of Berhane Hewan, which is now underway. Based on learnings from phase two, the Evidence Project developed a child census, a rapid tool that assesses the status of girls and boys in communities, including:

- Identifying sub-regions with the highest prevalence of girls who are out of school or married before age 18.

- Comparing the status of girls to boys to determine if there is a data-driven justification for a programmatic focus on girls.

- Contributing to evidence-driven programming for children and youth.

- Serving as a baseline for project interventions and calculating the universe of eligible girls.

Phase three looked at the importance of adaptation and local context. In phase one older girls were offered chickens to stay in school; this changed to solar-powered lights in the scale-up phase, which was designed with community needs and feasibility in mind. Some lessons garnered from these three progressive phases of Berhane Hewan include:

- The importance of demonstrating the use of evidence to build generations of effective and context-appropriate programs.

- How critical it is to use quality data to improve an understanding of programs, particularly for sensitive topics like child marriage.

- Flexibility and local context are vital to achieve scale-up of activities.

\section{Example of Research Utilization in the Context of an Emerging Evidence Base}

\section{Social Accountability Approaches to Improve Family Planning}

Victoria Boydell, the Evidence Project's rights and accountability advisor from the International Planned Parenthood Federation, presented on research utilization in the context of an emerging evidence base. She used examples from the project's work on how social accountability can impact the provision of services for family planning. She described the process of social accountability through an infographic developed by the Evidence Project (Figure 2). She discussed the fact that in 2014 there was a nascent evidence base for the impact of social accountability on improving family planning services. In her literature review, she found only 11 review papers and 16 case studies. She discussed the gaps in the literature that led to the Evidence Project leading or 
participating in several reviews, studies and working groups to advance the evidence base. Vicky explained the range of activities in which the Evidence Project has been engaged: studies, consultations, providing technical assistance, and, linking stakeholders. The graphic (Figure 3) depicts the "dead ends," activities that did not lead anywhere or remain dormant now.

Some lessons garnered from this work are that (a) it is important to participate in formal consultations and be present for conversations, (b) it is necessary to work on shared issues, and, (c) it is important to build on the work of others. It is also crucial to have the flexibility to take advantage of unexpected and unplanned opportunities and to expect some failure and dead ends as part of the process, particularly when working in an emerging area.

\section{Figure 2}

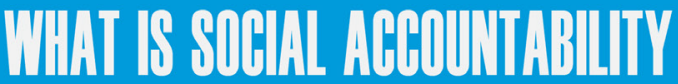

... and how is it used in family planning?

Engaged officials and health workers take action

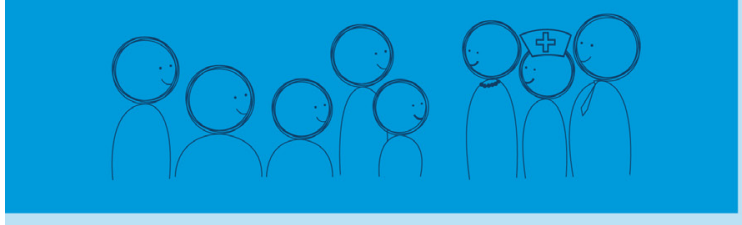

\section{Civic education}
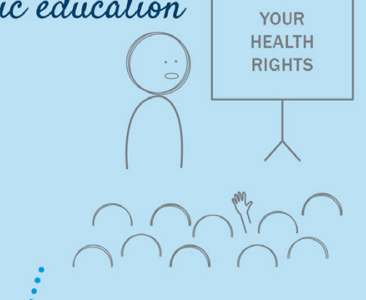

$\vdots$
$\vdots$
$\vdots$
$\vdots$
$\vdots$
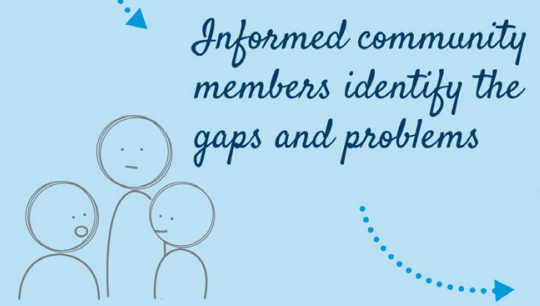

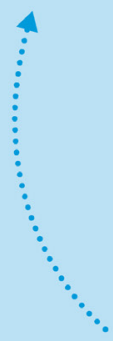

Informed community members engage officials and health workers
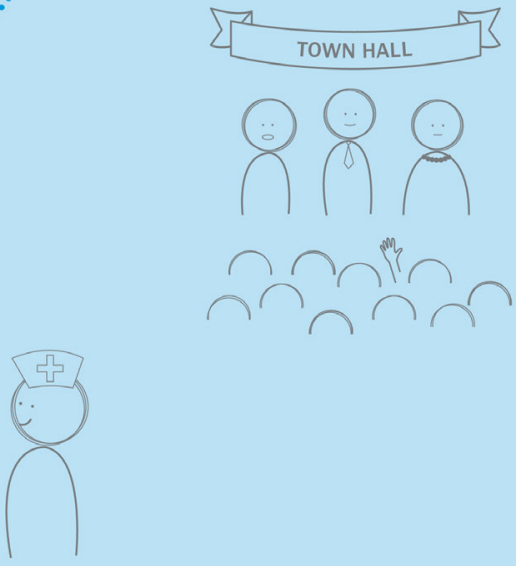

Informed community members

collect data and monitor
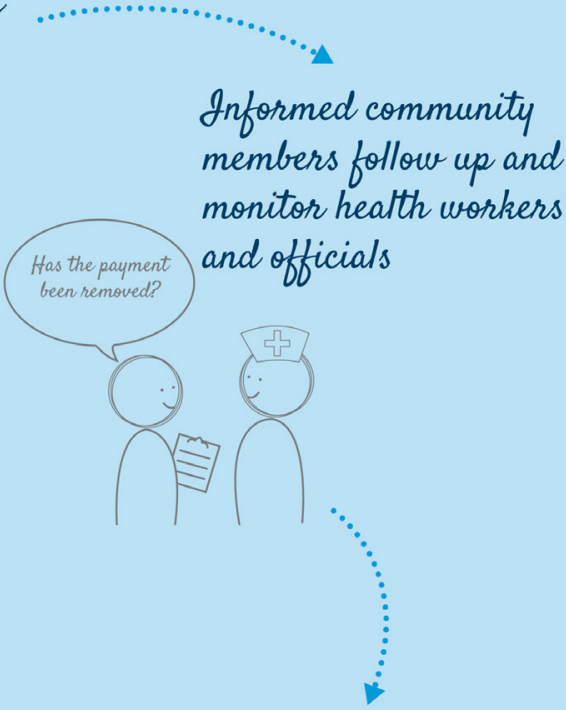

Together, informed community members and engaged officials help address inefficiencies and corruption, the allocation and effectiveness of programs, and improve family planning service. 
Figure 3

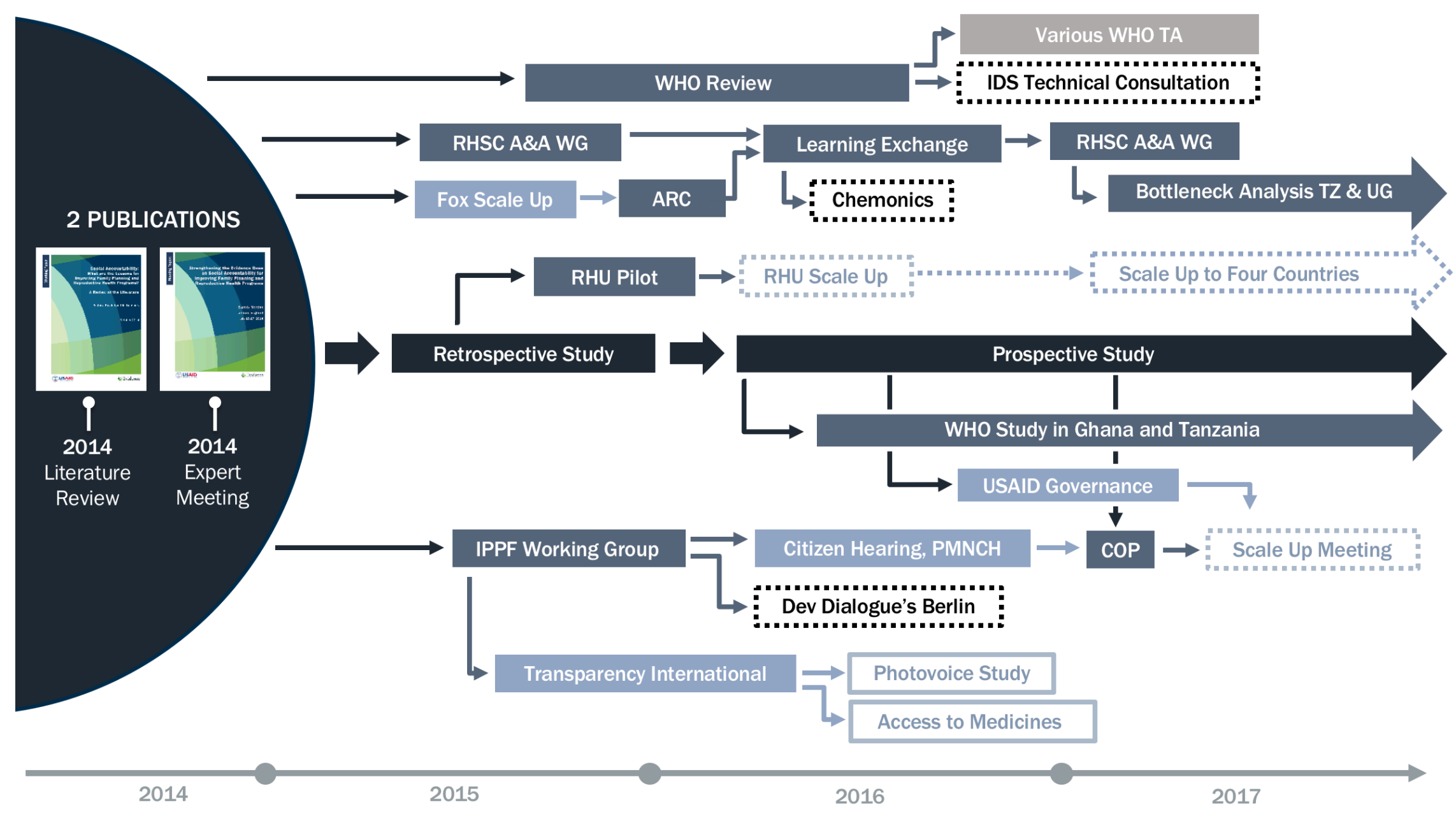

Key
Level of Evidence Project Involvement
High
Connections the Evidence Project made for others
Dormant activities




\section{Discussion}

Following the presentations, Karen Hardee facilitated a group discussion. Several key issues emerged from the discussion.

How to identify stakeholders/audience and how to meet their needs:

- What are the strategies to share primary data, both within organizations and with external audiences?

- How can researchers identify key audiences and connect to those who will benefit from the data?

- How do we help implementers identify and use existing evidence for their programming?

- How do we deal with research findings that may be contradictory to what a funder or government want to hear?

- How do we get findings to those who can use them, in a timely manner so that the results are still useful?

How to promote meaningful research utilization and high-quality studies:

- How do we ensure that the data being used is quality data? Not all data is good; it can be difficult to differentiate high quality studies from those of lower quality.

- How do we improve focus on costing data?

- How do we embed the concept of research utilization into research culture so that it is not just "ticking a box" but can have real impact?

How to pursue data collection at the appropriate geographic level:

- Research topics may be a donor-driven priority, not a country-driven priority, and the results not of high importance to a particular country.

- How do we get data to the sub-national level?

How to measure research utilization:

- How can utilization be measured and what are indicators of success?

How to address the need for data platforms and repositories:

- There is no organization to support searchable data collections; studies get replicated because people can't find existing data.

How to know what research we have that hasn't been used.

How to ensure negative findings are also in the public domain; this is important information, but less likely to be published.

How do we increase the evidence base on RU? Where and how can we publish information on RU? 
Some solutions were also discussed, including:

- Involve policy makers early in the process to find out what they really want to know. This can help the chance that the data will be used.

- Balance the optimum and the acceptable.

- Start with the data that exists when possible to save time and money: don't reinvent the wheel.

- If someone doesn't have a certain skill set, such as writing policy briefs, find someone who does to improve timeliness and quality.

- Begin the process by considering stakeholders' capacity and willingness to understand and accept results, understand any potential political sensitivity of results, and plan communications in line with these realities.

- Increase research utilization-related presentations in scientific meetings; increase visibility of RU among researchers and explain how it will improve the impact of their research.

- Increase dialogue between researchers and implementers. 


\section{Closing Remarks}

Michelle Hindin, director of reproductive health at the Population Council, closed the meeting by summarizing key messages:

- Context matters - we don't produce one size fits all results, but there are ways to communicate to broader audiences.

- What are you trying to answer or inform with your study? Hold yourself to the question you wanted to ask and don't be swayed by what you think people want to hear.

- If one size doesn't fit all, then how can we rush to scale up? You may have to make corrections for local context and wait to scale-up until all the evidence is there.

- The research community is not always great at sharing research among each other. What mechanisms can we think of to make sure that information gets out?

- How do we develop research utilization indicators and make sure they are the right ones?

- Don't be afraid to ask questions we don't know the answer to and don't be afraid of the answers. 


\section{Next Steps}

The Evidence Project will continue the rich discussion held at this meeting at future research- and implementationrelated meetings. It is beneficial to have these conversations with the both the research audience and the user audience. It is also important to bring them together so that the generators and consumers of research data better understand how to work together effectively.

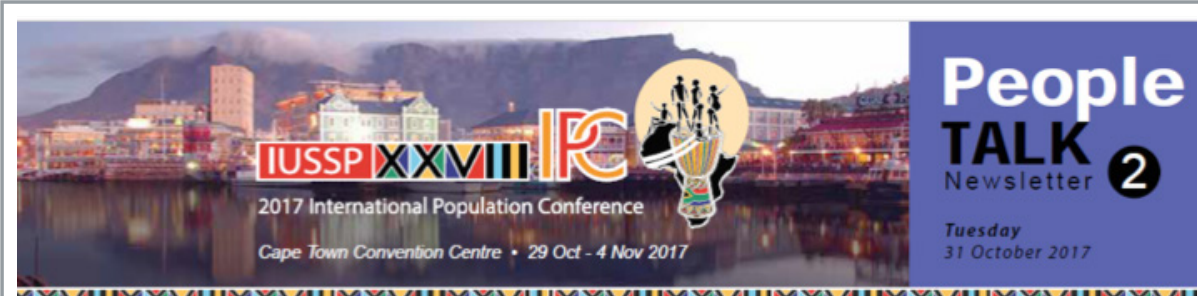

\section{MAKING THE VULNERABLE VISIBLE}

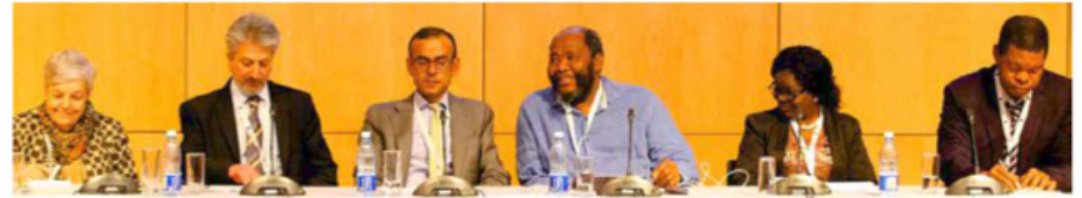

The United Nations Population Fund gathered a veritable who's who of the world of population study at the plenary session that closed off day one of the scientific programme of the IPC.

Dr Benoit Calasa, West and Central Africa Regional Director of the UNFPA, chaired the session which asked the panellists to consider how thechallenges posedbythe datademandsmade on the statistics community by Agenda 2030 for Sustainable Development can best be met. The panel, consisting of $\mathrm{Dr}$ Carmen Barasso, Regional Director of International Planned Parenthood Federation, Western Hemisphere Region (IPPF/ WHR); Professor Parfait Eloundou-Enyegue, Professor of Development Sociology, Cornell University; Dr Philomen Efua Nyarko, University of Ghana; Mr. Paulo Saad, United Nations Economic Commission for Latin America and the Caribbean; Professor Marwan Khawaja, UN ESCWA; and Dr Pali Lehohla, Statistician-General for South Africa and head of Statistics South Africa, carefully considered how best the world can meet the demand for disaggregated data that will ensure that the most vulnerable are made visible.

The importance of strategic partnerships with stakeholders other than National Statistical Offices (NSO) was highlighted. NSO's need to reach out to relevant stakeholders to partner with them in ensuring that the data needs of the SDGs are met. The coordination of this process is of paramount importance, in order to ensure that efforts are not duplicated. The panel also pointed to the importance of ensuring that the local national, regional and international development agendas are complementary, so that they work together decrease the turnaround times from data collection to the release of results. Big data has been used to track human movement in time of crisis, the earthquakes in Nepal and Haiti being examples of this.
It was proposed that this method could possibly be used to track the movement of displaced populations. It was pointed out that the research community can take credit for the shift to 'Leave No One Behind' that is the fundamental essence of Agenda 2030, as they were the ones who pointed out that the aggregated level of reporting in the Millennium Development Goals, in fact, meant that many were left behind.

Researchers were encouraged to stop thinking that their findings would magically lead to policy and investment that would best serve the population and to instead help build the political will to put the correct policies in place. They were challenged to spend the same amount of energy on the ground, as they did on the actual research; to partner with the broadest range of stakeholders possible to ensure that their research is used; to engage with and educate civil society and influencers so that these stakeholders are in a position to demand good data and use it to ensure that appropriate policies are put in place and actioned.

Researchers should have their ear to the ground and know what the most pressing issues are that need investigation. In this way, they can, by partnering with other interested stakeholders, improve society. An example of this is a study in Ghana which included academia and government, and that resulted in the Vitamin A Supplementation programme in Ghana, and which has been adopted by other areas in the world.

Let us all, especially those with the power to investigate, use our knowledge and skills to ensure that no-one is left behind.

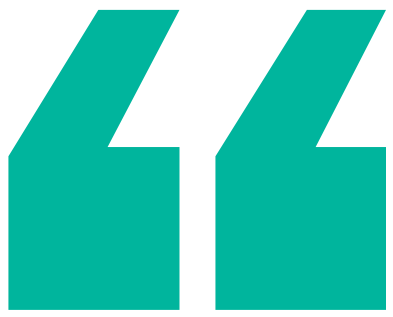

RESEARCHERS SHOULD NOT THINK THAT THEIR FINDINGS WILL MAGICALLY LEAD TO POLICY CHANGE."

Carmen Barasso, chair of the UN SecretaryGeneral's Independent Accountability Panel for Every Woman, Every Child, Every Adolescent, made the same point at both the Evidence Project Research to Action event and UNFPAsponsored session on data needs for the SDG. 


\section{Appendix 1 | Meeting Agenda}

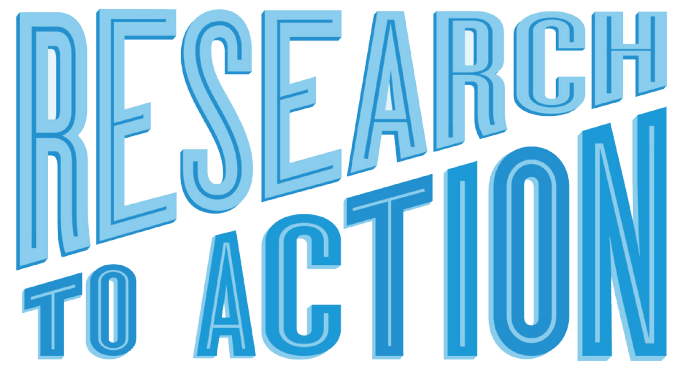

LESSONS AND LEARNING WITH THE EVIDENCE PROJECT

October 29, 2017 | 9:00am - 2:00pm

The Westin, Da Gama Conference Room

Cape Town, South Africa

\section{MEETING OBJECTIVES}

1. Gain an understanding of research utilization in the context of the Evidence Project

2. Learn about research utilization in different research contexts

3. Discuss and learn from others about challenges and ideas around research utilization

\begin{tabular}{|c|c|c|}
\hline $8: 45-9: 15$ & Registration and coffee & \\
\hline $9: 15-9: 30$ & Welcome and introductions & $\begin{array}{l}\text { Karen Hardee } \\
\text { Moderator }\end{array}$ \\
\hline $9: 30-9: 55$ & Researchers and research utilization & Ann Blanc \\
\hline $9: 55-10: 20$ & Research utilization approaches in the Evidence Project & Robin Keeley \\
\hline $10: 20-10: 45$ & $\begin{array}{l}\text { Research utilization for policy change: Proprietary and patent } \\
\text { medicine vendors and injectable contraceptives in Nigeria }\end{array}$ & Laura Reichenbach \\
\hline $10: 45-11: 05$ & $\begin{array}{l}\text { Research utilization to improve new programming: } \\
\text { Adolescent friendly health corners in Bangladesh }\end{array}$ & Sigma Ainul \\
\hline $11: 05-11: 30$ & $\begin{array}{l}\text { Research utilization to scale-up programming: Preventing } \\
\text { child marriage in Ethiopia }\end{array}$ & Aparna Jain \\
\hline $11: 30-12: 00$ & $\begin{array}{l}\text { Research utilization in the context of an emerging evidence } \\
\text { base: Social accountability approaches to improving family } \\
\text { planning }\end{array}$ & Victoria Boydell \\
\hline $12: 00-12: 45$ & Group discussion & $\begin{array}{l}\text { Karen Hardee } \\
\text { Facilitator }\end{array}$ \\
\hline $12: 45-1: 00$ & Wrap up & Michelle Hindin \\
\hline $1: 00-2: 00$ & Lunch & \\
\hline
\end{tabular}

\section{Evidence}




\section{Appendix 2 | Presentations}

All presentations presented at this event can be found at the following link

http://evidenceproject.popcouncil.org/resource/research-to-action-presentations-from-the-evidenceprojects-iussp-2017-side-event/

The presentations include:

Research Utilization Approaches in the Evidence Project

Robin Keeley

Research Utilization Specialist, The Evidence Project/PATH

Research Utilization for Policy Change: Proprietary and Patent Medicine Vendors and Injectable Contraceptives in Nigeria

Laura Reichenbach

Director, Breakthrough Research/Population Council

Research Utilization to Improve New Programming: Adolescent Friendly Health Corners in Bangladesh

Sigma Ainul

Population Council, The Evidence Project

Research Utilization to Scale-Up Programming: Preventing Child Marriage in Ethiopia

Annabel Erulkar

Country Director, Population Council Ethiopia

Aparna Jain

Deputy Technical Director, The Evidence Project/Population Council

Research Utilization in the Context of an Emerging Evidence Base: Social Accountability Approaches to Improving Family Planning

Vicky Boydell

Rights and Accountability Officer, The Evidence Project/IPPF 


\author{
(n)
}

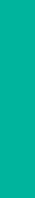

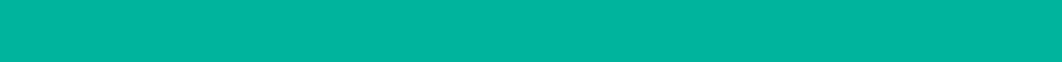

